\title{
Brief Meditation and the Interaction between Emotional Interference and Anxiety ${ }^{1}$
}

\author{
Carolina Baptista Menezes ${ }^{2}$ \\ Universidade Federal de Santa Catarina \\ Mirtes G. Pereira \\ Izabela Mocaiber \\ Universidade Federal Fluminense \\ Lisiane Bizarro \\ Universidade Federal do Rio Grande do Sul
}

\begin{abstract}
This pilot study assessed the effects of a five day focused meditation training on the interplay between emotional interference and anxiety in a non clinical sample randomized into two groups (experimental=13; control=18). Emotional interference was indexed comparing the reaction times in an attention span task with negative or neutral distracting images. Anxiety experienced during the task was also assessed through self-report. Only in the control group higher anxiety levels interacted with greater emotional interference and a worse evaluation of valence and arousal of emotional images. These preliminary findings suggest that meditation may help modulating anxiety effects on bias to negative stimuli, and that even a short training may facilitate self-regulatory processes.
\end{abstract}

Keywords: meditation, emotional interference, anxiety, self-regulatory processes

\section{Meditação breve e a interação entre interferência emocional e ansiedade}

\begin{abstract}
RESUMO - Este estudo piloto avaliou os efeitos de cinco dias de meditação focada na relação entre interferência emocional e ansiedade em amostra não clínica randomizada em dois grupos (experimental=13; controle=18). A interferência emocional foi indexada comparando os tempos de reação em uma tarefa de atenção com imagens distratoras negativas ou neutras. Também foi avaliado o autorrelato da ansiedade durante a tarefa. Apenas no grupo controle uma maior ansiedade interagiu com uma maior interferência emocional e uma pior avaliação de valência e alerta (arousal) das imagens emocionais. Esses achados preliminares sugerem que a meditação pode ajudar a modular o efeito da ansiedade no viés para estímulos negativos, e que mesmo um treino breve pode facilitar processos autorregulatórios.
\end{abstract}

Palavras-chave: meditação, interferência emocional, ansiedade, processos autorregulatórios

The increase in research on sitting and silent meditation has been generally accompanied by positive psychological results, such as reduced distress and anxiety symptoms, as well as improved well-being and regulatory skills (Chiesa, Serretti, \& Jakobsen, 2013; Lutz, Dunne, \& Davidson, 2007). Naturally, one question that arises relates to how much practice is necessary for these outcomes to take effect and, accordingly, different durations of meditation practice have been tested (Carmody \& Baer, 2009).

There is some evidence that interventions as short as a few days can already promote some expected changes. One such case comes from a study investigating a five days program called Integrative Mind Body Training (IBMT), in which practice was done for 20 minutes daily (Tang et al., 2007). Results showed a significant improvement in executive attention, as measured by the Attention Network Test, compared to a control group that did progressive relaxation for the same period (Tang et al., 2007).

1 Acknowledgment: Este estudo contou com o financiamento do Conselho Nacional de Pesquisa e Desenvolvimento Tecnológico (CNPq), FAPERJ e CAPES.

2 Endereço para correspondência: Psicologia, Universidade Federal de Pelotas, Avenida Duque de Caxias, n. 250, Fragata, Pelotas, RS, Brasil. CEP: 96.030-001.E-mail: para menezescarolina@hotmail.com
Tang et al. (2007) proposed that IBMT superiority over relaxation may be due to the combination of techniques that characterize the program, such as breathing, mental imagery, relaxation and meditation. However, positive results were also found with interventions using an exclusive meditation technique. For instance, one study that trained people for 4 days using a focused meditation practice for 20 minutes daily - compared to a group that trained attention by listening to an audio book - found significant improvements in sustained attention and mindfulness scores only in meditators (Zeidan, Johnson, Diamond, David, \& Goolkasian, 2010a).

Hence, the formal practice of meditation seems to account for attentional improvements and, importantly, evidence also extends to the emotional domain. After attending these interventions, participants significantly improved self-reports of mood, state anxiety, and decreased cigarette craving (Tang et al., 2007; Tang, Tang, \& Posner, 2013; Zeidan et al., 2010a; Zeidan, Johnson, Gordon, \& Goolkasian, 2010b). In addition, after an experimental induction of stress (Tang et al., 2007), and pain (Liu, Wang, Chang, Chen, \& Si, 2013), individuals who had undertaken a brief meditation training were better at reducing cortisol levels that had risen with the stressful situation, and at improving tolerance and distress during the pain experience, respectively. Also, similar amount of practice - 20 minutes for 7 days - helped participants decrease 
their evaluation of negative valenced pictures, which was accompanied by a reduced activity in the left amygdala (Taylor et al., 2011).

It is discussed that the combination of an attentive and a relaxed mind-body state is a key feature of meditation, likely responsible for the positive results observed (Lutz et al., 2007; Tang \& Posner, 2009; Wallace, 2008). This assumption is corroborated by the combination of results so far mentioned, as well as by the positive correlation found between indexes of central and autonomic nervous system regulation in participants of the IBMT intervention (Tang et al., 2009). Specifically, the pre-post theta wave increase in frontal midline anterior cingulate cortex (ACC) positively correlated with high frequency heart rate variability (Tang et al., 2009).

This finding is in line with the idea that ACC is involved in a form of attention that helps regulating cognitive and emotional processing (Bush, Luu, \& Posner, 2000), and whose function mediates parasympathetic activity (Critchley et al., 2003). Importantly, the correlation reported by Tang et al. (2009) not only elucidates that meditation generates greater balance between attention and relaxation, but also demonstrates that since an early stage of practice this combination may take effect, given that participants had undergone a five days training.

Noteworthy, the assumption that this balance may constitute the mechanism that enables meditation to promote positive psychological functioning seems to be supported by findings from the field of emotion regulation. Evidence shows that the use of cognitive strategies to regulate emotions, such as attention allocation, can be undermined by high levels of anxiety (Berggren \& Derakshan, 2013; Mocaiber et al., 2009; Sheppes, Luria, Fukuda, \& Gross, 2013), in line with results showing that affective states may be as important as cognitive skills for the regulation of emotions (Kanske \& Kotz, 2012).

\section{The Present Work}

The main objective of this research was to investigate the effects of a five day training in focused meditation (FM) on the interplay between emotional interference and anxiety in a non clinical sample of undergraduates. For this purpose, we assessed the interactions between interference indexes obtained through reaction times in a behavioral task, and the subjective ratings of experienced anxiety during the task.

The behavioral paradigm (Erthal et al., 2005) consisted of a negative arousing or neutral picture displayed in the center of the screen with a peripheral bar on each side of the picture. Subjects should look at the center, but ignore the image, and answer if the bars had the same orientation or not. The type of image (negative or neutral) and orientation (same or different) were randomly and equally distributed across trials. Also, in order to guarantee the attentional engagement in the relevant task, bars orientation could be presented in blocks with either a $90^{\circ}$ or a $6^{\circ}$ inclination difference.

Based on findings that even a short meditation training can benefit the practitioner on attention and emotional outcomes (Tang et al., 2007; Zeidan et al., 2010a), and that anxiety can undermine the cognitive regulation of emotions (Sheppes et al., 2013), we expected that for the focused meditation training emotion interference would not change according to anxiety levels.

\section{Method}

\section{Participants}

College students from the Universidade Federal do Rio Grande do Sul (UFRGS), southern Brazil, were invited to take part in the study through email and posters spread throughout three campuses. One hundred and twenty nine (129) students volunteered. Participants were excluded if they were not between 20-40 years old, did not have normal or corrected sight, reported any psychiatric or neurologic disorder, were taking any psychoactive medication, were undergoing psychotherapy treatment, and had had previous experience with meditation or yoga.

Initially, 46 eligible participants were equally and randomly assigned to one of two groups (focused meditationFM and wait-list control-WLC). The final sample comprised 31 participants [FM: $N=13,50,5 \%$ female, $100 \%$ single, Mage $=24.4$ years $(S D=4.27)$; WLC: $\mathrm{N}=18,67 \%$ female, $80 \%$ single, Mage $=24.4(S D=4.9)]$. These variables did not differ between groups $(p=>.05)$, and there was no significant difference in attrition rates $\left[\chi^{2}(1)=3.37, p=.09\right]$.

It should be noted that the study was carried out during the winter holiday period and on the week the intervention was delivered it rained very much during the five days which is usual at this time of the year in this region. Hence, we believe that the bad weather conditions influenced the higher drop outs in the meditation group, although we did not assess this information directly. In line with this assumption, after the posttest assessment, the 18 control participants who had remained in the control group underwent the five days training without any further drop outs. The study was approved by the Research Ethic Committee from the Institute of Psychology (UFRGS), under the registration number 25000.089325/2006-58, and all participants gave informed consent prior to assessment.

\section{Assessment}

\section{Screening tools}

Sociodemographic Questionnaire. This questionnaire was created for the present study in order to investigate sociodemographic and exclusion criteria variables.

Self-Report Questionnaire - SRQ (Harding et al., 1980). The SRQ consists of 23 questions that investigate minor and psychotic psychiatric symptoms through yes/no answers. The validated Brazilian version with sensitivity and specificity coefficients of $83 \%$ and $80 \%$, respectively, was used (Mari $\&$ Willians, 1986). The cut point for female and male was 7 and 6 positive answers, respectively. 


\section{Pretest and Posttest}

Discrimination Task - DT (Erthal et al., 2005). Figure 1 illustrates the trial structure, as well as the task rationale. Each trial initiated with a fixation cross, shown for $1.500 \mathrm{~ms}$. Next, a central picture $\left(9^{\circ} \times 12^{\circ}\right)$ and two peripheral bars $\left(0.3^{\circ}\right.$ $\mathrm{X} 3.0^{\circ}$ ) were presented for $200 \mathrm{~ms}$. The bars were at $9^{\circ}$ to the right and left of the center of the picture. A whole-screen checkerboard mask was then shown, remaining on the screen until the subject responded or for $2.000 \mathrm{~ms}$, which was the response deadline. The subjects were instructed to ignore the task-irrelevant central images and to respond as quickly and as accurately as possible whether or not the orientations of the peripheral bars were the same. Keypresses (with the right or left index finger) corresponding to same/different orientations ("q" or "p") were counterbalanced across subjects.

Two classes of images were employed: "neutral" and "emotional/unpleasant". Neutral images consisted of photographs of parts of the body or neutral faces, and unpleasant images consisted of photographs of mutilated bodies. We chose mutilated bodies because these are considered to be a very impacting category of emotional stimuli, likely to cause interference. Indeed, it has been already demonstrated that these images are efficient in generating an interference effect in the same paradigm used in the present study (Erthal et al., 2005).

One hundred and twenty different images, 60 neutral and 60 unpleasant were utilized. A different set of pictures was used in the pretest and posttest sessions and in each session pictures were repeated once. Forty-two images (14 neutral and 28 unpleasant) were taken from the International Affective Picture System (IAPS) developed by Lang and colleagues (Lang, Bradley, \& Cuthbert, 2005), and the remaining ones were obtained from the Internet.

For the internet images, the protocol developed by Lang and colleagues (Bradley \& Lang, 1994) was used for assessing valence and arousal $(N=20$, Mage $=22.3$ years, $S D=1.8)$. Overall, images in the neutral category had mean valence ratings of 5.0 and mean arousal ratings of 3.3; images in the unpleasant category had mean valence ratings of 2.2 and mean arousal ratings of 6.4 .

The experimental session started with three training blocks containing 20 trials each, which were followed by three regular blocks of trials ( 80 trials each). The order of neutral and unpleasant images within a block was randomized. During training blocks, all images were photographs of objects, such as tools and furniture. During each experimental block, the type of bar-orientation was fixed, and the two different orientations were obtained by manipulating the angular difference on nonmatching trials $\left(90^{\circ}\right.$ for one block and $6^{\circ}$ for two blocks). Each block contained the same number of match and nonmatching trials and the same number of neutral and unpleasant images.

Valence and arousal levels for emotional and neutral images presented in each block type were matched to avoid differences in emotionality between blocks. During the training blocks, participants received feedback, which indicated anticipatory responses (reaction times - RT - less than $100 \mathrm{~ms}$ ), slow responses (RT greater than $2.000 \mathrm{~ms}$ ), as well as whether an incorrect key was pressed; during training, the RT was also indicated on the screen after each trial. Experimental blocks, which followed the training blocks, lasted approximately five min each, and their order was randomized across subjects. The subjects sat approximately $60 \mathrm{~cm}$ from the display and the stimuli were presented with the software E-Prime.

Anxiety rating. An analog scale was used comprising one question about how anxious participants felt during the task. Answers were given on a 10 -point scale $(0=$ not at all, $10=$ very much)

Picture ratings. Participants viewed the pictures that had been previously presented in the Discrimination Task in order to assess their valence and arousal. In total, 4 blocks were presented: 20 negative pictures taken from the $90^{\circ}$ condition, 20 neutral pictures taken from the $90^{\circ}$ condition, 20 negative pictures taken from the $6^{\circ}$ condition, and 20 neutral pictures taken from the $6^{\circ}$ condition. For the $6^{\circ}$ condition, because there were two blocks during the behavioral task, the 20 negative and 20 neutral pictures were randomly selected from both blocks. For the 4 blocks, each image was displayed for $1 \mathrm{sec}$ and in the end participants had $15 \mathrm{sec}$. to rate the whole block using the paper-and-pencil version of the SelfAssessment Manikin (Bradley \& Lang, 1994). For both valence and arousal subjects rated from 1 (very unpleasant or very relaxing, respectively) to 9 (very pleasant or very alerting, respectively). Hence, the lower the valence score, the greater the unpleasantness, whereas the higher the arousal score, the greater the alertness.

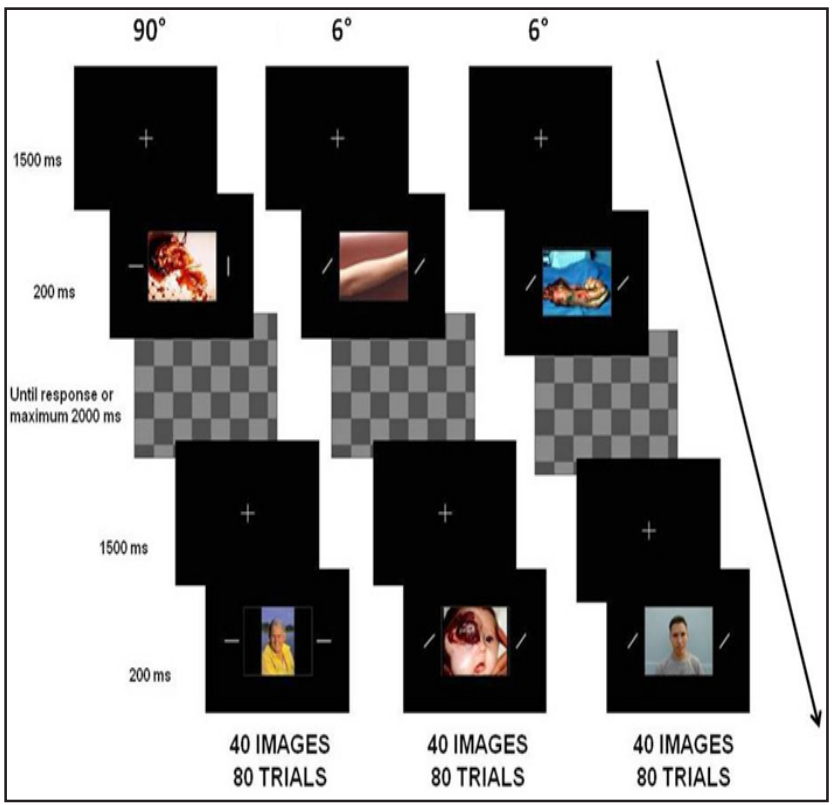

Figure 1. Experimental design: Across three blocks, in each trial a centered fixation cross was presented for $1.500 \mathrm{~ms}$, followed by a central picture with two peripheral bars presented simultaneously (for $200 \mathrm{~ms}$ ) to the right and left of fixation. A checkerboard-like mask was then presented, which remained on the screen until the response was made or until $2.000 \mathrm{~ms}$ had elapsed. Subjects were instructed to ignore the central picture and attend to the peripheral bars, responding with a keypress as quickly and accurately as possible whether the bars were in the same or a different orientation. Bars' orientation could be presented with either a $90^{\circ}$ or a $6^{\circ}$ inclination difference. 


\section{Design and Procedure}

This study comprised a pilot randomized controlled trial that relied on a factorial repeated measure design. Concerning procedure, after advertisement, volunteers interested in taking part in the study were sent the screening questionnaires online. Those eligible to participate were randomly allocated to one of the two groups. An email was sent to inform participants the group to which they had been allocated and requesting them to schedule a visit to the laboratory for the pretest session. Two assessments lasting approximately forty minutes, one at pretest and another at posttest (during the two weeks prior and after training, respectively), were carried out at the Laboratory of Experimental Psychology, Neuroscience, and Behavior, at the Institute of Psychology, UFRGS.

The following sequence of measures was used for both assessments: DT, Anxiety Rating, and Picture Ratings. FM training included five daily meetings, each lasting ninety minutes. WLC participants did not take part in any activity between testing sessions, but did receive the meditation training after final testing. Trainings were conducted by the first author, a psychologist trained on yoga, meditation and mindfulness practices, and with group experience. Meetings always started with a brief talk about participants' doubts, difficulties, or experiences during the rest of the day following the previous meeting, followed by instructions for practice, breathing exercises, formal meditation practice, and again a brief talk about the experience with that particular meeting.

In the two first meetings, formal practice lasted 15 and 20 minutes, respectively. For the following meetings, practices lasted 30 minutes. Participants could either sit crosslegged on a mat, or on a chair with their feet on the ground. Because everyone was a beginner, they were instructed to pay attention to the breath, trying to slightly prolong the exhalation. Also, in order to characterize focused meditation, and to try to guarantee they could maintain their focus to the meditation process and to the present moment, participants were instructed to count every exhalation (other types of focusing, such as the use of mantras, were not used in order to avoid any direct links to a specific philosophical or religious tradition). For the three first meetings, counting consisted of cycles of 1 to 10, and for the next two days, participants counted backwards from 100 to 1 (always one number per exhalation). Participants were not required to carry out extra practice outside the meetings.

\section{Data Analysis}

For DT analyses, all anticipatory and slow responses ( $<100 \mathrm{~ms}$ and $>2.000 \mathrm{~ms}$, respectively) were excluded; eliminated trials were infrequent at pre and posttest $(0.70 \%$ and $0.78 \%$ of the trials, respectively). Interference produced by the emotional pictures was analyzed relying on reaction times (RT) as dependent variables, and according to the following procedure: we calculated the RT means for each type of image and then created an index of emotion interference subtracting emotional from neutral values for each bar orientation, generating two factors (interference in the $90^{\circ}$ condition $x$ interference in the $6^{\circ}$ condition). The more positive the value, the greater the emotional interference.

Means for anxiety and picture ratings were also analyzed based on two factors (anxiety: high x low; valence: emotional $\mathrm{x}$ neutral; arousal: emotional $\mathrm{x}$ neutral). At pretest, a factorial general linear model (GLM) was used to assess the interaction between emotion interference $\left(90^{\circ} \times 6^{\circ}\right)$ and anxiety (high $\mathrm{x}$ low) as within factors, and group (FM x WLC) as a betweensubjects factor. Valence and arousal were separately analyzed for assessing their interaction with anxiety, considering type of images (emotional $\mathrm{x}$ neutral) and anxiety (high $\mathrm{x}$ low) as within factors, and group (FM x WLC) as between factor. At posttest, GLMs were carried out with time as an additional factor (T1 x T2). ANOVAs, polynomial contrasts, and pairwise comparisons using t-test were applied when appropriate. For all analyses, the Statistical Package for the Social Sciences (SPSS 20.0) was used, and the alpha level for statistical significance was $\mathrm{p}=.05$.

\section{Results}

\section{Pretest}

Discrimination task: Emotion interference. Emotion interference did not differ according to bar orientation $[F(1$, $44)=2.72, p=.11]$, and did not interact with group $[F(2$, 44) $=.82, p=.37]$.

Discrimination task: Anxiety x emotion interference. Ratings of anxiety did not interact with interference $[F(1,42)$ $=.22, p=.88]$, nor group $[F(1,42)=1.06, p=.31]$.

Picture ratings. There was a main effect of valence $[F(1,44)=465.45, p<.001$; emotional images were more unpleasant $(M=1.4, S D=.10)$ than neutral images $(M=5.8$, $S D=.17)]$, and a main effect of arousal $[F(1,44)=249.8, p$ $<.001$; emotional images were more arousing $(M=8.2, S D$ $=.15)$ than neutral images $(M=3.4, S D=.26)]$. There were no group interactions for valence $[F(1,44)=.11, p=.73]$, nor arousal $[F(1,44)=.92, p=.34]$.

Anxiety $x$ picture ratings. There were no significant interactions between valence $\mathrm{x}$ anxiety $\mathrm{x}$ group $[F(1,42)=$ $.98, p=.32]$, nor arousal $\mathrm{x}$ anxiety $\mathrm{x}$ group $[F(1,42)=2.6$, $p=.12]$.

\section{Posttest}

Socio-demographic data, as well as pretest measures were compared between drop-outs (participants who did not complete the study because they stopped attending the meetings) and completers (participants who completed training and both testing sessions), and no significant differences were found $(\mathrm{p}=>.05)$.

Discrimination task: Emotion interference. There were no interference $\mathrm{x}$ time $\mathrm{x}$ group interactions $[F(1,29)=2.54$, $p=.13]$ for the RT outcome.

Discrimination task: Anxiety x emotion interference. Total interference significantly differed according to anxiety ratings, time and group $[F(1,27)=4.63, p=.04]$. In the 
meditation group total emotional interference was null at posttest and did not differ between participants reporting low $(M=.85, S D=13.17)$ or high $(M=.45, S D=18.7)$ anxiety during the task $[t(11)=.02, p=.98]$, but in the control group total emotional interference was significantly higher in participants reporting high anxiety $(M=33.07, S D=11.41)$, compared to low anxiety $(M=-33.08, S D=16.13)[t(16)=$ $-3.15, p=.006]$ (Fig. 2).

Picture ratings. Ratings of emotional images remained more unpleasant $[F(1,29)=519.3, p<.001]$, and more arousing $[F(1,29)=295.7, p<.001]$ compared to neutral

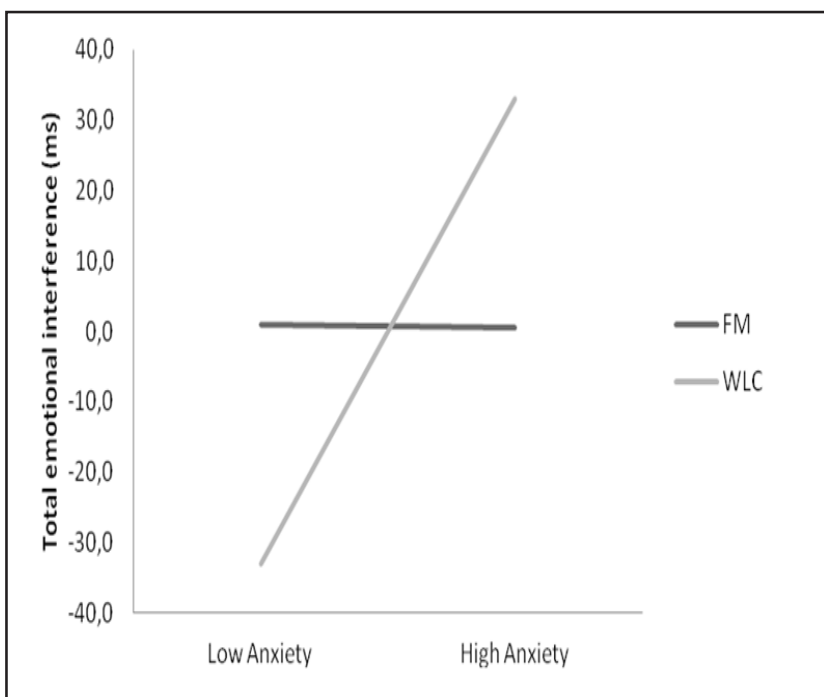

Figure 2. Mean values (ms)representing total emotional interference - for both bar orientation conditions - according to levels of anxiety experienced during the task for each group at posttest. $\mathrm{FM}=$ focused meditation; $\mathrm{WLC}=$ wait list control. A GLM for repeated measures indicated that at posttest total emotional interference did not differ between anxiety levels in the FM group, but it was significantly greater in control participants reporting higher anxiety. $\mathrm{p}<.05$

images across groups. There were no significant interactions between valence $\mathrm{x}$ time $\mathrm{x}$ group $[F(1,29)=.02, p<.87]$, nor arousal $\mathrm{x}$ time $\mathrm{x}$ group $[F(1,29)=.01, p<.89]$.

Anxiety $x$ picture ratings. There was a significant interaction between valence $\mathrm{x}$ anxiety $\mathrm{x}$ time $\mathrm{x}$ group $[F(1,27)$ $=7.17, p=.01]$ : at posttest. Meditators who reported either low or high anxiety during the task did not differ on valence ratings for emotional $[t(11)=.08, p=.93]$, or neutral $[t(11)$ $=-1.16, p=.27]$ images; in the control group, emotional images were rated as significantly more unpleasant among participants reporting high anxiety, compared to low anxiety $[t(16)=2.5, \mathrm{p}=.02]$, but no differences were observed for neutral images $[t(16)=-.68, p=.50]$ (fig. 3A).

The same interaction pattern was observed for arousal $[F(1,27)=6.28, p=.01]$ : at posttest, meditators who reported either low or high anxiety during the task did not differ on arousal ratings for emotional $[t(11)=-.73, p=.47]$, or neutral $[t(11)=-.01, p=.98]$ images, whereas in the control group emotional images were rated as significantly more arousing among participants reporting high anxiety, relative to low anxiety $[t(16)=-3.05, p=.007]$, but no differences were observed for neutral images $[t(16)=.00, p=1.0]$ (fig. 3B).

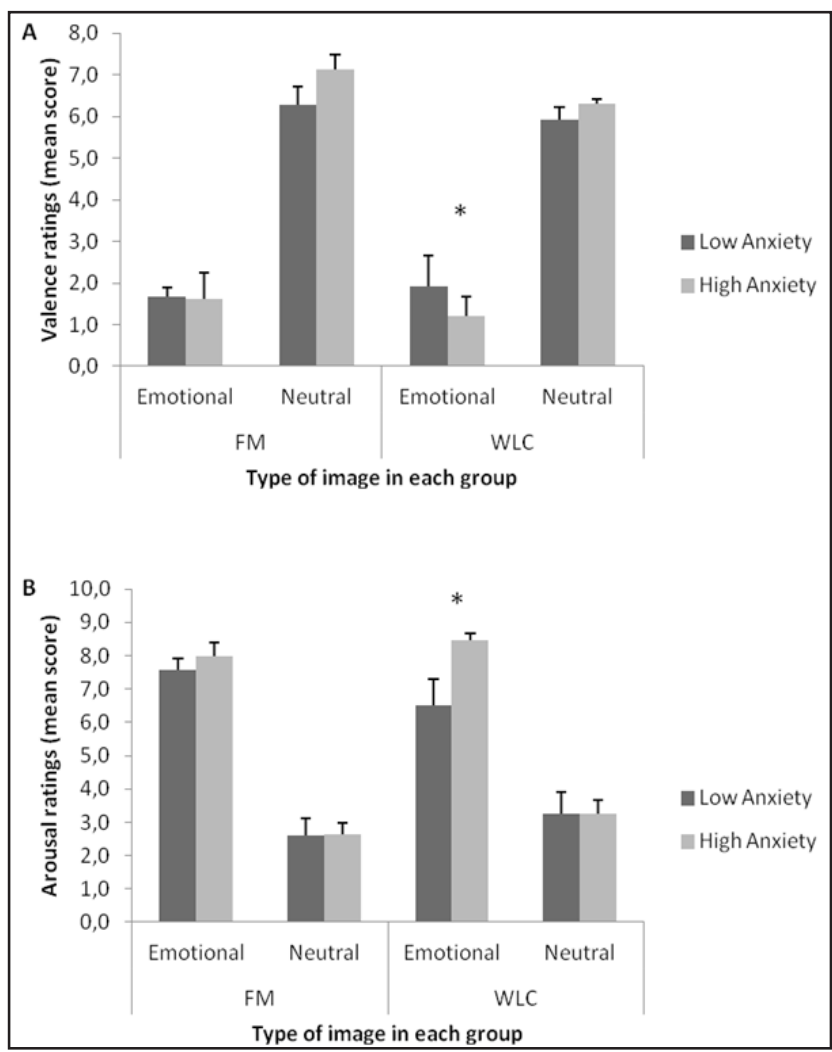

Figure 3A. Mean values representing valence ratings according to levels of anxiety experienced during the task for each type of image, in each group, at posttest. Standard errors are represented by the error bars. FM= focused meditation; WLC = wait list control. A GLM for repeated measures revealed that at posttest only in the WLC group emotional images were rated as significantly more unpleasant than neutral ones. 3B. Mean values representing arousal ratings according to levels of anxiety experienced during the task for each type of image, in each group, at posttest. Standard errors are represented by the error bars. FM= focused meditation; WLC = wait list control. A GLM for repeated measures yielded that at posttest only in the WLC group emotional images were rated as significantly more arousing than neutral ones at posttest. $* \mathrm{p}<.05$

\section{Discussion}

The present pilot study investigated whether a brief training in focused meditation, comprised of five consecutive daily practices, would influence the interplay between emotion interference and anxiety in a healthy sample of undergraduates. Emotion interference was indexed by reaction times obtained from a behavioral task, and anxiety experienced during the task was measured through selfreported ratings. Results showed that groups significantly differed on emotion interference according to anxiety level.

After meditating on average twenty minutes for five consecutive days, emotion interference was null for 
meditators reporting either low or high anxiety at posttest. However, for the wait list control group, emotion interference significantly differed according to anxiety levels: interference was greater among control participants reporting high anxiety experienced during the task. This result was corroborated by the finding that also only in the control group participants reporting high anxiety during the task rated emotional images as significantly more unpleasant and more arousing.

From a psychological perspective, evidence shows that higher levels of anxiety can influence bias to negative emotions (Bishop, 2007), undermine the effectiveness of cognitive regulation of negative emotion (Mocaiber et al., 2009; Sheppes et al., 2013), and interfere in the performance of conflict resolution for negative emotional stimuli (Kanske \& Kotz, 2012). More recently, it has been demonstrated that anxiety is particularly impairing in the context of disengaging attention from negative stimuli (Sheppes et al., 2013). Even though our task did not test the disengagement hypothesis directly, we believe this rationale might explain our results, given that in our task the participants' gaze was directed to the center of the images, even though they were instructed to orient their covert attention to the peripheral bars.

Hence, whereas in the control group higher anxiety levels may have likely impaired the disengagement from the distracting negative stimuli presented during the attentional task, meditators seem to have been better able to modulate this interaction. Also, the impairing influence of anxiety on the disengagement from negative stimuli might help explain why control participants reporting higher anxiety were more responsive to the unpleasantness and arousal of emotional images.

On one hand, from the standpoint of emotion regulation, the presence of better attentional control seems capable of attenuating the influence that high anxiety can exert on bias to negative stimuli (Derryberry \& Reed, 2002; Morawetz, Baudewig, Treue, \& Dechent, 2010). However, on the other hand, anxiety has the potential of interfering with attention allocation in the context of emotional stimuli (Oliveira, David, Volchan, \& Pereira, 2013; Sheppes et al., 2013).

Thus, in line with some propositions about sitting and silent meditation, either focused or open monitoring (Lutz, Slagter, Dunne, \& Davidson, 2008; Tang \& Posner, 2009; Zeidan et al., 2010a), we suggest that in spite of being derived from a short term intervention, our findings represent outcomes that may be related to the skills that the practice of meditation aims to foster. In particular, improved attention regulation, a more relaxed basal state, and the balance between these skills (Lutz et al., 2007; Tang \& Posner, 2009; Tang et al., 2009; Wallace, 2008).

Accordingly, it was observed that when novices practice ten minutes of focused meditation an attention network consisting of the anterior cingulate, insula and frontalparietal regions is significantly more recruited compared to a mind wandering condition (Dickenson, Berkman, Arch, \& Lieberman, 2012). Also, one study assessing the effects of a brief four days meditation training demonstrated that meditators presented a significant improvement in sustained attention as measured by working memory tasks, as well as reduction in state anxiety, which the authors hypothesized to be likely interrelated (Zeidan et al., 2010a). Moreover, in support of these results, after five days of IBMT training the increased activation in theta wave in the anterior cingulate cortex positively correlated with parasympathetic activity (Tang et al., 2009).

The finding that meditation has the potential to modulate the interaction between anxiety and emotional interference - perhaps through fostering a greater balance between attention regulation and relaxation - may have important implications for a more positive psychological functioning. For instance, in line with our results on valence, one study found that individuals who practiced meditation for twenty minutes during seven days were less reactive to negative stimuli, according to their subjective evaluation of negative valenced pictures, as well as to the neural correlate of reduced activity in the left amygdala (Taylor et al., 2011).

Another example of implication relates to the finding that a brief meditation training was able to reduce cigarette craving (Tang et al., 2013). We suggest this reduction might have resulted from the meditators' ability to better control the interference of cues associated with the drug, and to reduce attentional bias to these stimuli, which are processes known to normally lead to craving or to the drug use behavior (Peuker, Lopes, Menezes, Cunha, \& Bizarro, 2013). Likewise, this potential modulation may help reduce the hazardous interference and impact of stressful stimuli, in line with findings that participants of brief meditation trainings, compared to controls, significantly reduced cortisol levels following an experimental stress induction (Tang et al., 2007), and significantly improved tolerance and the experience of distress during an experimental induction of pain (Liu et al., 2013).

Importantly, the present study shows preliminary results corroborating the idea that some meditation benefits may take effect since an early stage of practice (Tang et al., 2007; Tang et al., 2009; Tang et al., 2013; Taylor et al., 2011; Zeidan et al., 2010a, 2010b). Nevertheless, it should be noted that comparing novice and expert practitioners yields distinct effects. For instance, more reduced activation of some default mode network regions of the brain in the context of emotional appraisal was observed in long term meditators, indicating less self referential processes and strengthened present moment awareness (Taylor et al., 2012). Also, more systematic comparisons of different types of meditation trainings are necessary to confirm whether the observed effects comprise core processes of all kinds of practices, or whether it is possible to disentangle particular effects for distinct meditation techniques. Data obtained from some of the cited studies derived from different meditation trainings, such as IBMT (Tang et al., 2007; Tang et al., 2009; Tang et al., 2013), which combines meditation, relaxation and guided imagery, as well as mindfulness (Taylor et al., 2011), which implies a more broad-monitoring awareness, in opposition to the exercise of strictly focusing attention on one object (Lutz et al., 2008), such as in the focused meditation training taught in the present study.

Finally, our findings contribute to the discussions regarding the mechanisms that underlie and foster emotion regulation skills (Bishop, 2007; Derryberry \& Reed, 2002; Kanske \& Kotz, 2012; Mocaiber et al., 2009; Oliveira et al., 2013; Sheppes et al., 2013), and support the proposition 
that meditation may be a valuable strategy for the study of regulatory processes (Menezes, Pereira, \& Bizarro, 2012). However, our results should be extended and complemented by larger scale trials, as well as by the usage of more ecologically valid measures. In addition, because the present study investigated a healthy sample, the question of whether such a short-term training would benefit clinical populations remains unanswered.

\section{Conclusion}

Despite some limitations, such as sample size, high rate of drop-outs, no power calculation, lack of an active control group, and no follow up assessment, this pilot study suggests that a five day training in focused meditation may be able to foster emotion regulation skills by modulating the interaction between emotion interference and anxiety.

It is hypothesized that this effect may result from an improved attention regulation and a more relaxed basal state, as well as from their interplay. The present findings support the idea that short term trainings may produce some psychological benefits since an early stage of practice. The results also suggest that this is a relevant finding, because early effects might function as an important reinforcement for a more regular and long term practice.

\section{References}

Berggren, N., \& Derakshan, N. (2013). Attentional control deficits in trait anxiety: Why you see them and why you don't. Biological Psychology, 92(3), 440-446. doi:10.1016/j. biopsycho.2012.03.007

Bishop, S. J. (2007). Neurocognitive mechanisms of anxiety: An integrative account. Trends in cognitive sciences, 11(7), 307-316. doi:10.1016/j.tics.2007.05.008

Bradley, M. M., \& Lang, P. J. (1994). Measuring emotion: The SelfAssessment Manikin and the Semantic Differential. Journal of Behavior Therapy and Experimental Psychiatry, 25(1), 49-59.

Bush, G., Luu, P., \& Posner, M. I. (2000). Cognitive and emotional influences in anterior cingulate cortex. Trends in Cognitive Sciences, 4(6), 215-222. doi:10.1016/S1364-6613(00)01483-2

Carmody, J., \& Baer, R. A. (2009). How long does a mindfulnessbased stress reduction program need to be? A review of class contact hours and effect sizes for psychological distress. Journal of Clinical Psychology, 65(6), 627-638. doi:10.1002/ jclp. 20555

Chiesa, A., Serretti, A., \& Jakobsen, J. C. (2013). Mindfulness: Top-down or bottom-up emotion regulation strategy? Clinical Psychology Review, 33(1), 82-96. doi:10.1016/j. cpr.2012.10.006

Critchley, H. D., Mathias, C. J., Josephs, O., O’Doherty, J., Zanini, S., Dewar, B. K., Cipolotti, L., Shallice, T., \& Dolan, R. J. (2003). Human cingulate cortex and autonomic control: Converging neuroimaging and clinical evidence. Brain: A Journal of Neurology, 126(Pt 10), 2139-2152. doi:10.1093/ brain/awg216
Derryberry, D., \& Reed, M. A. (2002). Anxiety-related attentional biases and their regulation by attentional control. Journal of Abnormal Psychology, 111(2), 225-236. doi:10.1037/0021843X.111.2.225

Dickenson, J., Berkman, E. T., Arch, J., \& Lieberman, M. D. (2012). Neural correlates of focused attention during a brief mindfulness induction. Social Cognitive and Affective Neuroscience, 8(1), 40-47. doi:10.1093/scan/nss030

Erthal, F., Oliveira, L., Mocaiber, I., Pereira, M. G., MachadoPinheiro, W., Volchan, E., \& Pessoa, L. (2005). Load-dependent modulation of affective picture processing. Cognitive, Affective, \& Behavioral Neuroscience, 5(4), 388-395.

Harding, T. W., Arango, M. V., Baltazar, J., Climent, C. E., Ibrahim, H. H. A., Ladrido-Ignacio, L., ... Wig, N. N. (1980). Mental Disorders in primary health care: A study of their frequency and diagnosis in four development contries. Psychological Medicine, 10, 231-241. doi:10.1017/S0033291700043993

Kanske, P., \& Kotz, S. A. (2012). Effortful control, depression, and anxiety correlate with the influence of emotion on executive attentional control. Biological Psychology, 91(1), 88-95. doi:10.1016/j.biopsycho.2012.04.007

Lang, P. J., Bradley, M. M., \& Cuthbert, B. N. (2005). International affective picture system (IAPS): Affective ratings of pictures and instruction manual (Technical Report A-6). Gainesville, FL: University of Florida.

Liu, X., Wang, S., Chang, S., Chen, W., \& Si, M. (2013). Effect of brief mindfulness intervention on tolerance and distress of pain induced by cold-pressor task. Stress and Health: Journal of the International Society for the Investigation of Stress, 29(3), 199-204. doi:10.1002/smi.2446

Lutz, A., Dunne, J. D., \& Davidson, R. J. (2007). Meditation and the neuroscience of consciousness: An introduction. In P. Zelazo, M. Moscovitch, \& E. Thompson (Orgs.), Cambridge handbook of consciousness (p. 499-554). New York: Cambridge University Press.

Lutz, A., Slagter, H. A., Dunne, J. D., \& Davidson, R. J. (2008). Attention regulation and monitoring in meditation. Trends in Cognitive Sciences, 12(4), 163-169. doi:10.1016/j. tics.2008.01.005

Mari, J., \& Willians, P. A. (1986). A validity study of a psychiatric screening questionnaire (SRQ-20) in primary care in the city of São Paulo. British Journal of Psychiatry, 148, 23-26.

Menezes, C. B., de Paula Couto, M. C., Buratto, L. G., Erthal, F., Pereira, M. G., \& Bizarro, L. (2013). The improvement of emotion and attention regulation after a 6-week training of focused meditation: A randomized controlled trial. EvidenceBased Complementary and Alternative Medicine: eCAM, 2013, 984678. doi:10.1155/2013/984678

Menezes, C. B., Pereira, M. G., \& Bizarro, L. (2012). Sitting and silent meditation as a strategy to study emotion regulation. Psychology \& Neuroscience, 5(1), 27 - 36. doi:10.3922/p\&n. v5i1.225

Mocaiber, I., Pereira, M. G., Erthal, F. S., Figueira, I., MachadoPinheiro, V., Cagy, M., ... Oliveira, L. (2009). Regulation of negative emotions in high trait anxious individuals: An ERP study. Psychology \& Neuroscience, 2(2), 211-217. doi:10.3922/j.psns.2009.2.014 
Morawetz, C., Baudewig, J., Treue, S., \& Dechent, P. (2010). Diverting attention suppresses human amygdala responses to faces. Frontiers in Human Neuroscience, 4(226), 226. doi:10.3389/fnhum.2010.00226

Oliveira, L., David, I. A., Volchan, E., \& Pereira, M. G. (2013). Emotion and attention interaction: a trade-off between stimuli relevance, motivation and individual differences. Frontiers in Human Neuroscience, 7, 364. doi:10.3389/fnhum.2013.00364

Peuker, A. C., Lopes, F. M., Menezes, C. B., Cunha, S. M., \& Bizarro, L. (2013). Implicit processes and drug addiction: Theory, assessment and future directions. Psicologia: Teoria e Pesquisa, 29(1), 07-14. doi:10.1590/S010237722013000100002

Sheppes, G., Luria, R., Fukuda, K., \& Gross, J. J. (2013). There's more to anxiety than meets the eye: Isolating threat-related attentional engagement and disengagement biases. Emotion, 13(3), 520-528. doi:10.1037/a0031236

Tang, Y., Ma, Y., Fan, Y., Feng, H., Wang, J., Feng, S., \& Fan, M. (2009). Central and autonomic nervous system interaction is altered by short-term meditation. Proceedings of the National Academy of Sciences, 106(22): 8865-8870. Recovered from http://www.pnas.org/content/106/22/8865.full?sid=81c57e1c1c7a-4ce0-8c73-bdd9b7914538

Tang, Y., Ma, Y., Wang, J., Fan, Y., Feng, S., Lu, Q., Yu, Q., Sui, D., Rothbart, M. K., Fan, M., \& Posner, M. I. (2007). Short-term meditation training improves attention and self-regulation. Proceedings of the National Academy of Sciences, 104(43), 17152-17156.
Tang, Y., \& Posner, M. I. (2009). Attention training and attention state training. Trends in Cognitive Sciences, 13(5), 222-227.

Tang, Y., Tang, R., \& Posner, M. I. (2013). Brief meditation training induces smoking reduction. Proceedings of the National Academy of Sciences of the United States of America, 110(34), 13971-13975. doi:10.1073/pnas.1311887110

Taylor, V. A., Grant, J., Daneault, V., Scavone, G., Breton, E., Roffe-Vidal, S., Courtemanche, J., Lavarenne, A. S., \& Beauregard, M. (2011). Impact of mindfulness on the neural responses to emotional pictures in experienced and beginner meditators. NeuroImage, 57, 1524-1533. doi:10.1016/j. neuroimage.2011.06.001

Taylor, V. A., Daneault, V., Grant, J., Scavone, G., Breton, E., RoffeVidal, S., ... Beauregard, M. (2012). Impact of Meditation Training on the Default Mode Network During a Restful State. Social Cognitive and Affective Neuroscience, 8(1), 4-14 doi:10.1093/scan/nsr087

Wallace, B. A. (2008). A revolução da atenção: Revelando o poder da mente focada. Petrópolis: Vozes.

Zeidan, F., Johnson, S. K., Diamond, B. J., David, Z., \& Goolkasian, P. (2010a). Mindfulness meditation improves cognition: Evidence of brief mental training. Consciousness and Cognition, 19(2), 597-605. doi:10.1016/j.concog.2010.03.014

Zeidan, F., Johnson, S. K., Gordon, N. S., \& Goolkasian, P. (2010b). Effects of brief and sham mindfulness meditation on mood and cardiovascular variables. The Journal of Alternative and Complementary Medicine, 16(8), 867-873. doi:10.1089/ acm.2009.0321 